This item was submitted to Loughborough's Research Repository by the author.

Items in Figshare are protected by copyright, with all rights reserved, unless otherwise indicated.

\title{
The influence of practice culture on designed artefacts
}

\section{PLEASE CITE THE PUBLISHED VERSION}

http://dx.doi.org/10.1017/S1359135516000051

\section{PUBLISHER}

(c) Cambridge University Press

\section{VERSION}

AM (Accepted Manuscript)

\section{PUBLISHER STATEMENT}

This work is made available according to the conditions of the Creative Commons Attribution-NonCommercialNoDerivatives 4.0 International (CC BY-NC-ND 4.0) licence. Full details of this licence are available at: https://creativecommons.org/licenses/by-nc-nd/4.0/

\section{LICENCE}

CC BY-NC-ND 4.0

\section{REPOSITORY RECORD}

Schmidt, Robert, and Andrew Dainty. 2016. "The Influence of Practice Culture on Designed Artefacts". Loughborough University. https://hdl.handle.net/2134/23970. 
The influence of practice culture on designed artefacts

\section{Authors}

Robert Schmidt III (r.schmidt-iii@lboro.ac.uk), and

Professor Andy Dainty (a.j.r.dainty@lboro.ac.uk)

\section{Affiliations}

${ }^{1}$ Department of Civil and Building Engineering, Loughborough University

28 word Abstract (currently 30 words)

We seek to understand the influence of practice culture in shaping the designed outcome, connecting process and product, giving importance to the socio-material context in which the outcome is created.

\section{Acknowledgements}

The research has been graciously funded by the Loughborough IMCRC (Innovative Manufacturing and Construction Research Centre) through the EPSRC (Engineering Physical Science Research Council). The work would not have been possible without the support of the architecture practice depicted in the paper along with a very giving and helpful project architect. 


\section{Introduction}

It is by taking an internal view of the design practice that all the multifarious aggregates that link design together can be appreciated. ${ }^{1}$ Here, the practice and its processes account for the distinctive features of design, which are themselves set in the everyday trajectories of the practice as a co-operative activity of people and objects. Furthermore, design is not only a product of social relations, but can also be seen to play out across and through other registers, such as embodied actions or material artefacts. ${ }^{2}$ Seen in these ways, the design practice serves as an arena for these activities and becomes an active agent in shaping the designed outcome. Despite the intuitive attraction of such a perspective, which sees design practice and the resultant architecture as being enmeshed, the literature points out the fallacy of industry's focus on the built artefact as a static object and the individual architect as a stable image of creativity. ${ }^{3}$ Such perspectives remove any sense of a long and intertwined design and use process. If, on the other hand, design is viewed as a complex and on-going social accomplishment it can be seen to be continually shaped by contingent forces, both internal and external to the designer. This view of design is often expressed from an ethnographic point of view ${ }^{4}$ in which the 'social' network of forces, or socio-material relations, are in constant negotiation with each other through an iterative and dynamic process that inevitably defines what is eventually designed.

In this paper we seek to construct a more dynamic picture of architecture by connecting process and product, supplementing a project narrative with one of practice, and giving importance to the context in which the outcome was created. In this vein, we proffer the research question - how does practice culture become intertwined within the designed product? Our theoretical disposition is that the culture of design practice cannot be separated from the built artefact and thus we aim to generate new theoretical provocations around the role of practice in designing buildings. We seek to ground the often abstract conversation around the culture of practice through the resultant artefacts that it produces. This sees design as a socio-material process, shaped by contingent forces, but playing out within a physical arena that is in itself an active agent in the design process, mediating the space between client and exogenous demands and supply.

The research chose to focus on a particular design consideration in an effort to help direct and ground the study. By deliberately focusing on a single design consideration (adaptability) we have a clearer criterion for which to consider the relationship and performance of the designed solutions. Adaptability while seemingly a straightforward design aspiration, is often a contested topic making its inclusion uncertain and dependent on a range of potential obstacles including additional costs, short-term business models, lack of price signals, discounting future costs, etc. Hence, although the focus on adaptability in this context serves as a means to an end relative to the larger intent of this paper, it offers an appropriate design criterion through which to reveal the ways in which practice culture both mediates, and is translated and embedded into designed artefacts.

\section{Towards a typology of design practice}

Cuff $^{5}$ argues that few architects would speak of 'cultural differences' as a way of distinguishing between practices, but conventionally refer either to a portfolio of projects, or the types of services the practice may offer. Similarly, 
Blau ${ }^{6}$ points out that most analysis of architectural practice has been either historical or of the style and use of their buildings. However, viewed another way, professional practice can be seen as a complex, but systematic social organisation that embodies a culture of underlying patterns through the everyday activities of its people, instilled beliefs and espoused values, or in other words, an organized way of ordering relations to social or physical environments. ${ }^{7}$ Cuff concludes that a practice can be seen as a unique and dynamic environment, a cultural microcosm, organised around: a) a charismatic individual(s) or a set of collaborative objectives which maybe for economic reasons, b) specialisation and diversity and/ or c) to establish a meaningful world. Seen in these terms, design culture extends beyond what is manifested in an artefact to the totality of carrying out design or as Julier ${ }^{8}$ positions "from conceiving and negotiating artefacts with clients, to studio organization, to the output of the design and to its realization."

Cultural typologies and frameworks of organizations abound, but one of the most influential is that developed by Schein $^{9}$, who analyses the culture of an organization at several different levels comprising: beliefs (basic assumptions that are implicit in the way people work), values (espoused attitudes, strategies and behavioural norms), and artefacts (things that you can see). While Schein examines the broader role of leadership in organisations, this simple schema relates well to the exemplified structure used by Cuff ${ }^{10}$ to define the culture of architectural practice - dialect, mores, activity patterns, power structure and roles. Cuff goes on to additionally clarify that discussing the practice as an active agent does not dismiss the agency of the lone architect in the process, but gives significance to the context, the social underpinnings, in which the individual acts. Seen in this way, the practice becomes an arena for a building's formative life, and influential in the way the individual designer works. ${ }^{11}$

In seeking to position practice within the context of a broader competitive context, Coxe et al. ${ }^{12}$ define three strategic approaches for positioning a practice within the context of the construction industry - strong delivery offers a reliable solution through repeat design elements and lower fees (straight forward projects); strong service offers a capacity to solve more complex aspects to projects (e.g. programme, planning permission, scale) and can charge a higher fee; and strong ideas have a strong reputation in the field for a unique and creative nature and can also charge higher fees. Winch and Schneider ${ }^{13}$ augment Coxe et al.'s approach by offering a fourth approach - strong ambition (new practices who are qualified, but with little experience and charge low fees to gain work) - and argue for the (re)positioning of the approaches more appropriately against measures of market positioning opposed to the choice of technology used by Coxe et al. - project complexity (simple - complex) and quality preference (peer - client) - see Figure 1. The axes provide a helpful depiction with regards to practice dispositions, however they do little to situate the different approaches against the forces at play and the resulting architecture. In other words, they do not anchor their rhetoric to the tangible products of design. 


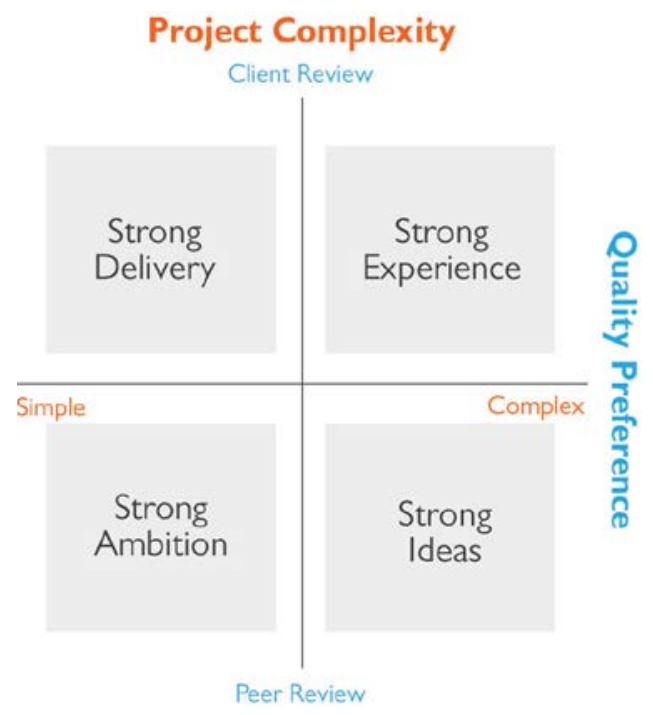

Figure 1 Winch and Schneider (1993) Practice Typologies

In their study Coxe et al. add another important distinction between organisational approaches through their fundamental values. A 'Practice-centred business' is focused around producing quality examples of the profession and serving others. They are qualitatively-driven as architecture is 'a way of life'. In contrast, a 'Business-centred practice' is focused on the bottom-line or tangible reward for their efforts. They are more likely to be quantitatively-driven as architecture is 'a means of livelihood'. They note that all practices operate somewhere in-between the two extremes, but that the distinction between which one is primary is important. While not one and the same, this distinction resonates with Winch and Schneider's ${ }^{14}$ quality preference axis. This fundamental distinction is also picked up on by Blau's Daeldian Risk ${ }^{15}$, revealing the tension in attempting to satisfy clients (more quantitative) and professional peers (more qualitative). Larson ${ }^{16}$ further elaborates this tension by suggesting that an architect's reputation is made through publications, awards, professional societies etc., that have more to do with fellow architects' approval (qualitative values) than with past clients and suggests this dependent heteronomy makes architectural practice different than other professions (e.g. law, medicine) which have more of a monopolistic control. Hence, the way in which a practice defines their approach (e.g. strong delivery) and positions their fundamental values (e.g. practice-centred business) will have a strong effect on the culture of their practice.

The role of the architect

The literature reveals a range of perspectives on the role of the architect and their relationship with architectural practice. Jenkins ${ }^{17}$, for example, suggests that after WWII the architect inherited the role of creating a more humane environment (i.e. a broader social service) as well as the traditional roles of artist and businessman. This tri-partite role was reinforced by Cohen et al. ${ }^{18}$, who identified three entangled roles the architect as a profession endures - architecture as creative endeavour (artist), architecture as business activity (businessman) and architecture as public service (humanitarian). Cohen's et al. identified roles do not suggest three types of 
architects, but are analytical constructs to discuss the dynamics at play. Architecture, presented as a creative endeavour, is casted by many as the architect's defining role, 'their aesthetic sensibility and skill' which brings 'beauty', 'style' and 'rhythm' to buildings. ${ }^{19}$ Architecture as a business activity relates to the successful economic operation of the practice towards a 'good track record', 'profitability' and 'efficiency' (the client's side of Blau's Daeldian Risk). Architecture as a public service supports Jenkins' claim that architecture extends beyond oneself for the collective good inspired by social values such as building safety and longevity. Hence, the way in which a practice views and operationalises the three defined roles of an architect will influence how the practice handles the contingent forces at play and moulds the resultant architecture.

\section{Linking practice culture and the resultant artefact}

In chapter III of Book I from de Architectura (The Ten Books on Architecture), Vitruvius describes three principles that architecture must adhere to: firmness, commodity and delight. ${ }^{20}$ Contemporary translations can be described as strength or good engineering (firmness), function or habitability (commodity) and beauty or visual pleasure (delight). ${ }^{21}$ This architectural axiom has served as a driver and indicator of 'good design' for over two millennia. A modern day example of its application is Design Quality Indicators (DQI) which its framework (build quality, function and impact) for assessing design quality is based on Vitruvius' three basic roles for architecture. ${ }^{22}$ This tripartite of architectural building quality maps well to the distinct roles of the architect and helps to contextualise the theoretical space between the stable practice and temporary projects. This relationship forms a link between process and product from which we can structure the forces at play. A similar shaping of contingent forces is posited by Tschumi ${ }^{23}$ when describing his practice's portfolio of projects, as the interplay of three forces - concept (ideas), context (site) and content (programme). Tschumi's depiction of forces are focused on the practice (concept) and project (context and content) levels; whereas, Brand ${ }^{24}$ suggests technology, market and fashion as three forces that exist outside of the practice and project specifics. In combination, design can be seen to be 'pulled' by factors which either sit inside the practice, inside the specifics of the project, or outside both. These three distinct environments form the corners of the model proposed and allow for relationships to be drawn with the three roles of architectural practice (process) described by Cohen et al. and the three roles of architecture (product) as described by Vitruvius - Figure 2. 


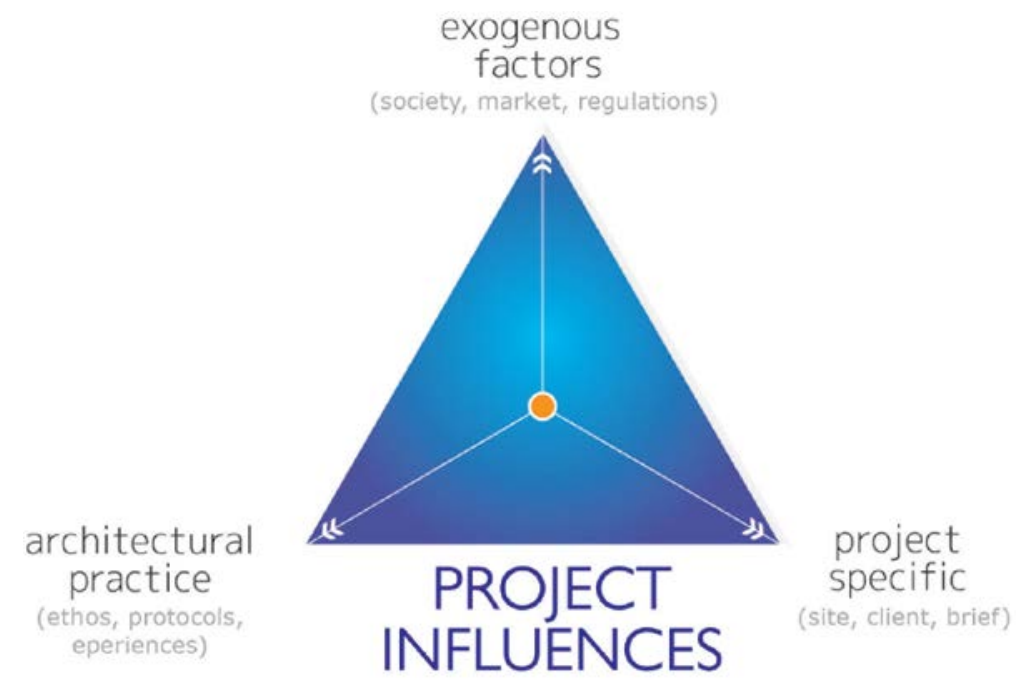

Figure 2 Conceptual Model (research lens)

Thus, we position our research lens as a product of the desired qualities of architecture and the distinct roles of the architect as a way of discussing the forces at play within the design process that shape the resultant architecture. The architectural practice (history, structure, ethos) as the primary designer of the building relates the strongest to delight (beauty; creative endeavour). The project specific (client, design team, site) is rooted in the particulars of the project and focused on making something that works, a commodity (function; business activity). The exogenous factors (legislation, industry bodies, public) extend beyond the particular project and oversee, assess and value the safety, longevity and sustainability towards firmness (build quality, public servant).

Winch and Schneider's practice approaches and Coxe et al. defined value types are visualised on the triangle as illustrated in Figure 3. The triangle can be split vertically (forming two sub-triangles) with the left side forming a theoretical space for qualitative values (practice-centred businesses) and the right side for quantitative values (business-centred practices). Further delineation can be made given Winch and Schneider's project complexity distinction with simpler projects (strong ambition, strong deliver) creating sub-triangles along the bottom axis reducing the complexities often presented through exogenous factors. Thus, the ability to model practice and product allow for conclusions to be drawn with regard to the influence practice culture plays on the resultant architecture. 


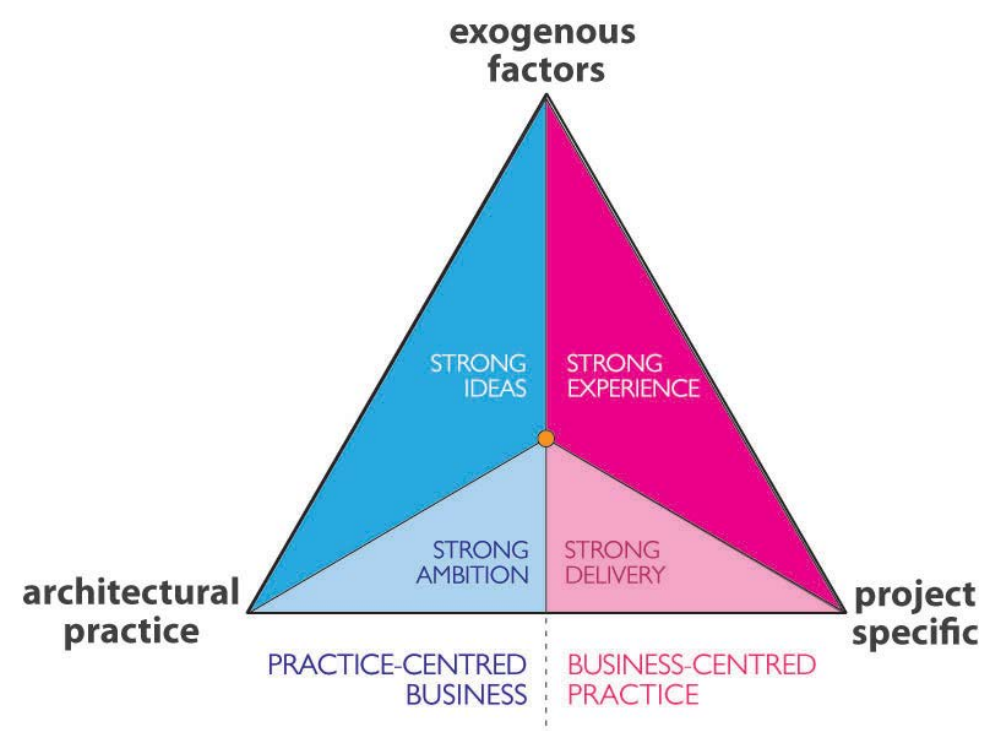

Figure 3 Mapping Practice Approaches and Values onto the model

In our research this model provided a basis for a dialogue with practitioners discussing the socio-material context in which design takes place, as well as providing a way of simplifying the milieu of complex forces at play. In other words, it served as a framework within which to capture the parameters influencing the design process and to clearly link the culture of practice with the adaptability of the resultant design, drawing out clear distinctions between practices and projects. We deployed the model to explore the prominence of designing for adaptability within practices with different practice dispositions, and moreover, whether a particular emphasis might enable adaptability to become foregrounded within the design processes. The intent here is not to judge practice, but to provide a commentary on how the various 'pulls' might influence the architecture that it produces and by doing so respond to the main research question at hand - how does practice culture become intertwined within the designed product?

\section{Focus on adaptability}

All buildings will inevitably change throughout their lives, and so designing buildings in ways that can adapt to accommodate change cost-effectively arguably represents a key design criterion. ${ }^{25}$ An increased capacity to adapt our buildings can offer benefits in the form of waste reduction, lower energy consumption, reduced operational costs and shorter downtime, as well as potential benefits to the character and quality of the building. ${ }^{26}$ This research adapts the following definition of adaptability: 'the capacity of a building to accommodate effectively the evolving demands of its context, thus maximising its value through life'. ${ }^{27}$ Adaptability in this context is primarily concerned with change during the use phase of buildings, whereas other sources refer to its application or links with other design strategies targeted at the pre-use phases such as industrialisation and end-of-life phases. ${ }^{28}$

Adaptability, while important to sustainability, is not a heavily regulated design parameter like energy or carbon - thus it is not forced upon designers and remains a largely discretionary topic for consideration. ${ }^{29}$ Given 
the often discretionary nature of adaptable design, its association with practice values should be all the more prominent. In addition, adaptability's enmeshment with time (and change) makes it overtly sensitive to the longevity of design decisions and their contingent effects - it entangles the design and operation of the building making its consideration less straightforward and often subordinated below other more immediate design considerations. Thus, depending on the type of client, adaptability can find itself high (long-term, investment developer) or low (short-term, merchant developer) on the priority list. This raises the question in relation to how adaptability, as one of an array of design issues, can be scaled, evolved, prioritised and stabilised through the design process? Lastly, the literature rarely expands the consideration of adaptability beyond the physical parameters of the building (e.g. storey height, plan depth), making it ripe for a broader consideration of influences - e.g. planning regulations ${ }^{30}$, market conditions ${ }^{31}$ and procurement routes. ${ }^{32}$ Therefore it is adaptability's discretionary, contentious and marginal nature that make it an ideal topic for investigating the role practice plays with regards to influencing the resultant architecture.

\section{Research Method}

A case study approach was chosen to evolve the theory abductively. The research deployed Dubois and Gadde's strategy of systematic combining (theory-matching) ${ }^{33}$ which shares methodological similarities with Glaser and Strauss' Grounded theory ${ }^{34}$ and Eisenhardt's building theory from case studies approach ${ }^{35}$, but emphasises the co-evolution of data collection and theory from the beginning of the process. Whereas grounded theory suggests no a priori framework, systematic combining advocates an initial framework (proposed model above) that can be tested while generating it, allowing the theory to evolve and match the evidence. In this respect systematic combining is more about theory development than theory generation. Thus, rather than theorize significant elements of 'practice culture' a priori we followed abductive logic drawn upon extent theory, whilst retaining an open mind as to emergent features of practice that were inductively derived through the empirical work. The process was operationalised with the research question - how does practice culture become intertwined within the designed product?

The research was conducted in two stages taking place over a 12 month period. The first stage was a series of interviews (40 design practices) which provided a flexible method to gain a broader range of insights into the everyday accounts of the interviewees' practice culture and its relationship to designing for adaptability. ${ }^{36}$ The interviews took the form of a 'general interview guide approach', which allowed for the same general areas of information to be collected while allowing the interviewer a controlled level of freedom to probe areas of interest based on the interviewees' responses. The comparative approach helped to reveal the artefacts, espoused values and behaviours, and pointed towards some of the underlying assumptions that enabled creative solutions to emerge. Subsequently, each practice was 'plotted' on the model - Figure 4. The practice location on the model was based on the resulting tendency of the practice's general position in project examples. Thus, the location should not be interpreted to necessarily represent the practice's ideal positioning of themselves, nor do they 
represent a static position, but merely an attempt to characterise the practices described disposition through their work at a moment in time.

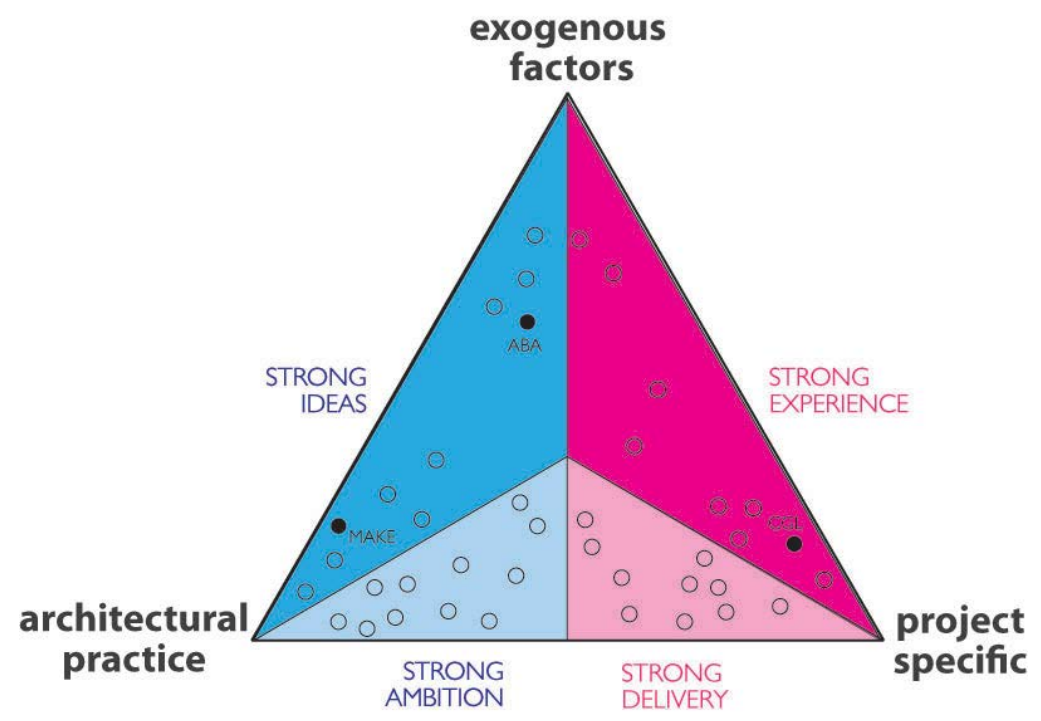

Figure 4 Practice Dispositions plotted on model

For the second stage, project case studies were selected as a strategy to further investigate the topic with a more in-depth yet bounded context-based understanding. ${ }^{37}$ Three exemplars of the practice archetypes were chosen to follow up with an in-depth case study analysis of a single project (three black dots on Figure 4) in order to examine how a particular practice ethos might shape the resultant architecture. The practice depictions plotted on the model were used as a means to distinguish between dissimilar practice typologies, allowing for a range of practice types to further investigate - i.e. we deliberately chose quite polarized examples to best illustrate the theoretical argument (Figure 4). The selection of the three practices was then a result of differentiation (location on the model) and practicalities (willingness and timing). The rationale for the selected projects was determined by timing (current or recently completed), adaptability as an overt consideration, and the availability of project documentation. Data was subsequently collected through additional interviews, project documentation, and practice observations.

\section{Case studies}

Make Architects (Make)

Our first meeting with Make was at a satellite office, located in a mixed-use building, not on one of the upper floors designed for office use, but on the ground floor, a 'retail' space, with an all glass façade placing the practice and its activities on display for the public to see (and occasionally walk in on). A row of work stations and adjacent round tables are surrounded by a continuous flow of images showcasing the practice's work along the walls, only broken to establish their brand more explicitly as the company logo in bright red letters stretches across the pristine back wall. The space itself is branded with their 'red \& white' persona as the surfaces are accompanied by 
carefully chosen furniture of the same colour and modern style. One can quickly get the sense that design (making beautiful buildings) is at the core of what they do.

The practice was founded in 2004 as a result of a charismatic leader deciding to break away from a successful practice to form and shape a new practice. The practice has grown exponentially from the original handful to approximately 180 'partners' with three offices in the UK and abroad. The organization embraces an employee ownership model in which no explicit hierarchy exists; everyone shares in decisions, profits and a collective responsibility for the destiny of the practice. This is reflected in the practice's name, not of the individual leader(s), but as a message of what they do - Make. The practice embraces an informal mode of operations in an effort to attract intelligent, creative individuals.

The heterarchical character of the practice is not just in terms of their management style, but also in terms of the way in which they approach design. They adopt an ethos of 'an attitude' rather than 'a style', a state of mind, not attached to any single driving force for their architecture. The design process typically starts by a very intimate engagement with the site and client. This specific response (sometimes the catalyst) is coalesced with a single design concept that distils one guiding principle to aid with design decisions. Rules may be attached to the concept as well, but all follow a single clear logic that adds rationality to decisions and helps position a clear conceptual and formal argument for the design.

\section{The Cube}

The 'perfect' Cube is a newly constructed iconic building situated prominently with a strong visual presence and a clear identity that is anchored to a powerful design concept. The aesthetic originates from a painting by the founder that underwent a digitalisation process to provide a 'realistic' foundation from which to work from and apply to the context. The formal vision is then intertwined with its location, Birmingham, having a long history in jewellery manufacturing, the visual concept evolves into a jewellery box; a beautiful metal cube on the outside with glass and colour on the inside. It is clear that all other design criterion (including adaptability) must accommodate the strong design concept. Here, adaptability is driven completely from the client-side, originating from the success of their neighbouring mixed-use predecessor The Mailbox.

The Cube (Figure 5) is a series of vertically stacked uses with transitional floors that can be used as either the use above or below (e.g. level 8 can be used as an office or A1/A3 retail). This solution is perceived as optimal, rather than designing every floor to the 'lowest' common denominator. Tailoring the floor zones, varying floor to floor heights, floor loadings, fire strategies, lift and service strategies, somewhat restricts the potential convertibility of the solution, but allows the number of floors within the cube concept to be increased and allows money to be spent in other ways while providing a degree of adaptability to the solution.

The framed structure and servicing strategy creates an open and versatile floor plan that allows floor plates to be subdivided based on tenant needs. Again, the overall size of the plan was fixed based on the cube concept; thus the space provided for an interior courtyard varies at levels to accommodate programmatic shifts. The unique spatial character of the courtyard driven by the architect was balanced with the maximum structural cantilever, maximum width for the office floor plate and appropriate depths for apartments (project specifics) 
creating a hugely iterative process of balancing elements. While the jagged geometry of the courtyard facades create wedge shaped interior spaces somewhat difficult to use, the courtyard offers several positive features for the potential adaptability providing a unique character, a shared public space, visible circulation, good day lighting and views. The example here illustrates how a solution can be positive for adaptability in one way (courtyard), while potentially compromising in another (apartment space plan) - a simpler façade solution for the courtyard could have ameliorated the tension, but would have impeded the design concept.

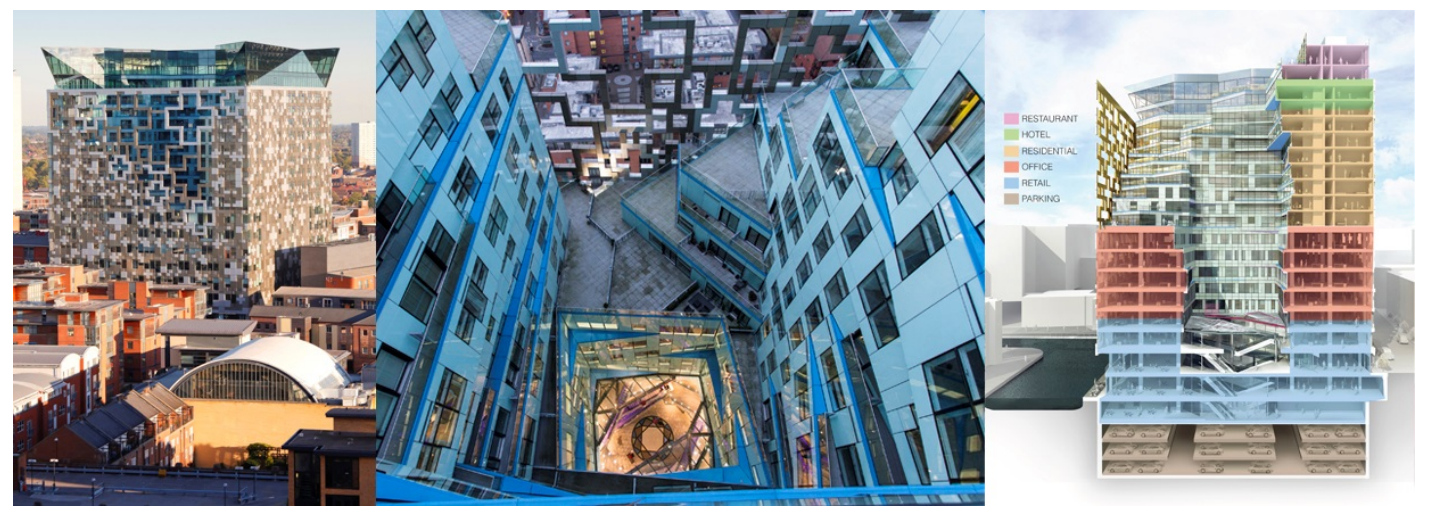

Figure 5 The Cube, Make Architects (Images courtesy of Crew Photography, David Ryle and Make Architects)

Early on it was discovered that the building would exceed the intended budget. Conventional perception is to reduce the capital cost of the building (e.g. select cheaper materials or scale down the building) in order to trim the budget, but in the Cube's case it jeopardised the integrity of the concept. With an alternate approach, the design team proposed adding two floors to the building that could be let as additional apartments, increasing the capital cost, but given the long-term position of the client, the raised annual revenue made for good value. The concept of the jewellery box was therefore stabilised, but the adaptability of the building is now endangered by the designer's own admission that a more generous floor to floor height is critical in allowing for alternative uses. The overall height of the building is locked (the 'perfect' cube) which means either the concept is broken or the additional floors fit within the predetermined overall height of the building (the latter was chosen). While the example illustrates a level of malleability in the design allowing for the building section to be changed, it ultimately diminishes the future adaptability (alternative uses) by reducing floor to floor heights.

\section{Alison Brooks Architects (ABA)}

ABA's office is grounded in a strong design-orientated community, located in Camden (known for its artistic and alternative cultures) in a group of renovated warehouse buildings marketed at creative organisations. Upon entering the practice's space the visitor can't help but focus on the bold acidic yellow floor contrasted by its allwhite surroundings (walls, ceilings, furniture). The studio space is completely open; the desks are adjacent to a set of small round tables that provide an open and informal setting for meetings and have publications and awards lying on the bordering window sill. Traces of creativity are scattered throughout - a sketch temporally hung on the brink of falling, physical models distributed on the tops of shelves, project boards strategically placed on walls and photos of celebrated projects randomly sprinkled on the white surfaces. 
Similar to Make, ABA was founded by a charismatic leader breaking away from a long-time partnership with an established practice. Over the past 16 years, the practice has built an award-winning portfolio by winning open and invited competitions, referrals and their reputation. The current practice is fifteen members strong with a hierarchical structure branching down from two directors, an associate, project architects and architectural assistants. As an established part of their practice, a large amount of their work comes in a range of residential projects from housing associations and private clients. Staff are rewarded with responsibility and reward packages and are supported to attend CPD events regularly, Health and Safety courses to achieve various qualifications and encouraged to engage in cultural events.

Within the practice, architecture is seen as city-building, designing the physical and cultural infrastructure for social interactions. This belief is supported through an intensely site-specific approach establishing a cultural, political and physical connectivity to the site. The research-intense approach underpins design decisions and often manifests itself in the aesthetic and materiality of the building. The approach is combined with the practical understanding that a building has a use and it must perform the basic requirements of the client's brief, "It can be the most stunning building in the world, but it shouldn't be rewarded if doesn't fulfil the users' needs."

\section{Folkestone Performing Arts Centre (FPAC)}

Over the last century, the centre of Folkestone has lost much of its vibrant life. The Creative Foundation was established in 2002 to spearhead an art-led regeneration programme for Folkestone, of which the Folkestone Performing Arts Centre (FPAC) is a centrepiece and catalyst for an emerging arts quarter. For ABA, the context became the main driver, attempting to tap into aspects that form part of a collective memory. The design concept stemmed from Renaissance myths, representing the scallop shell as a local symbol of the pilgrimage soldiers undertook down Main Street to the pier. Architecturally, this is embraced through the translucent nature of curved façade panels painted a scallop shell pink and softly lit from behind in the evening reinterpreting the local architectural symbolism of the shells as architraves over windows - Figure 6.
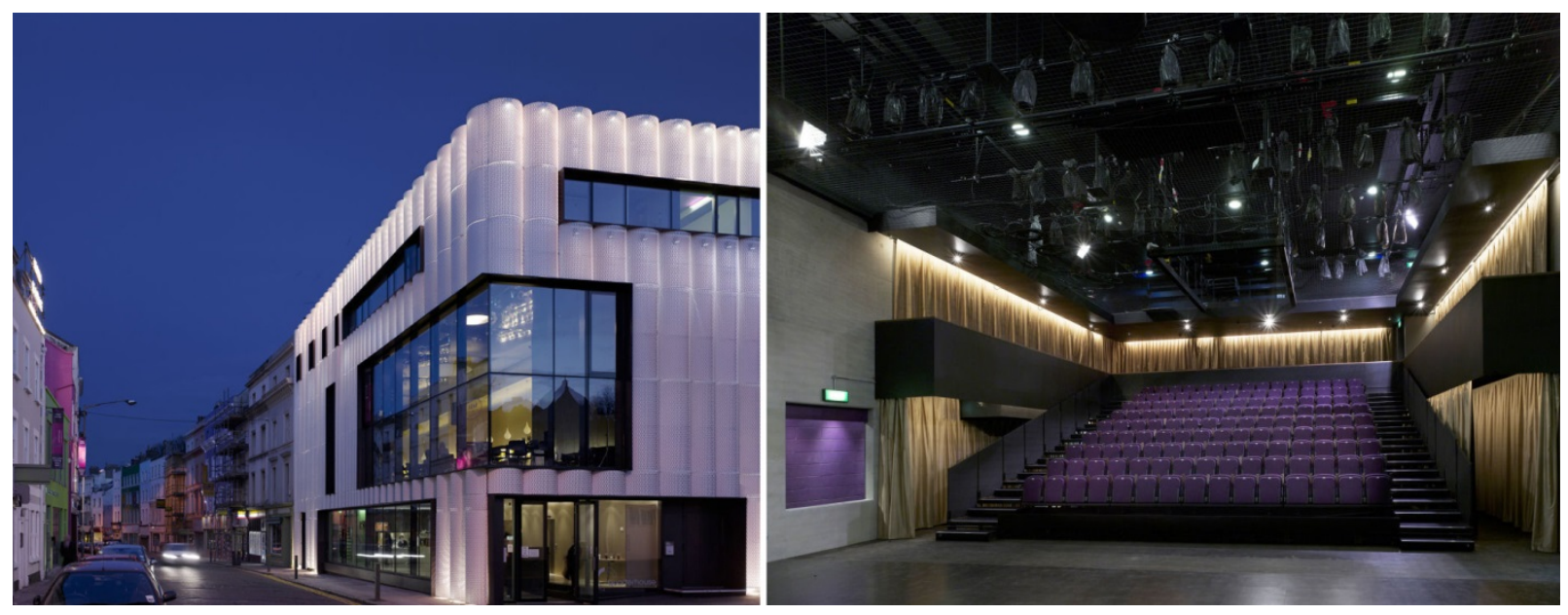

Figure 6 Folkestone Performing Arts Centre, Alison Brooks Architects (Images courtesy of Dennis Gilbert) 
Proportions, height of floors and the overall building height all relate to the neighbouring Georgian buildings, but at the same time don't attempt to replicate the architectural style or materials. To this point, the chief planning officer was against the use of expanded metal mesh for the facade given the historic Georgian high street. However, ABA was able to appeal to the planning committee by weaving the materiality of the facade into the before mentioned historic narrative, illustrating its potential beauty through a strong concept of place and thus legitimizing the use of the material to the committee. Attention was also given to how the neighbouring sites would develop over time and how the building could complement new uses around it. While the building has not been designed to be added to vertically, it has been designed to be 'scaled' horizontally if the Creative Foundation is able to acquire the adjacent site across the street. The plan creates a public space that would link to events and performances as a forecourt and in effect scaling the space and use of the building.

FPAC is thoughtfully designed to be used in a variety of ways (combining cultural and commercial uses). The design of the top floor plan has already allowed it to adapt to a change in the market. The openness of the space (depth of the plan, amount of daylight, column spacing and storey height) allowed for what was to be a large restaurant to easily become incubator offices with the addition of interior partitions - offering a range of business suites, meeting rooms and one large versatile space that can be leased out for special occasions and catered to from the restaurant on the first floor. The space could easily be changed again, if there were to be another shift in the market, to residential units for example. In another example, the theatre space was designed and labelled as a multi-purpose community space as opposed to a fixed theatre (250 seated, 450 standing, and 100 cabaret style). The seats inside the theatre can be retracted, allowing the space to be used for conferences, weddings, community events, etc. The space could cater to more uses if a large window (natural light) was included, but acoustic glass was outside the budget and the window was lost. Another option that could be implemented later is exterior doors, allowing the space to open directly onto the street and operate as a separately secured facility.

Furthermore, the over-sized circulation space on the ground floor is used as a gallery and reception space for when the theatre is in use, but can also be used to hold events or converted into another use in the future such as retail. The bar \& restaurant on the first floor is open independent of the theatre and services the offices above along with the surrounding community. The varied activities within the building are representational of ABA's desire to extend the value of the building to the larger physical and social context and generates an intriguing overlap between how the building is used throughout the day, week and year.

\section{Child Graddon \& Lewis Architects \& Designers (CGL)}

Located in Shoreditch near the Old Spitalfields Market, the path to CGL's office leads the visitor through a metal louvered gate, revealing a hidden courtyard filled with trees, outdoor furniture and a bright mural that stretches across the entrance wall - discriminately disclosing the practice's initials. At the back of the semi-private sanctum is the entrance, an old dairy building dating back to the Victorian era is (re)framed with a contemporary glass and metal storefront projecting a formal meeting space. Branded sweets and brochures along with architectural publications sit on a polished concrete bar for visitors to scan and take. The office is split into two levels, the 
ground floor additionally contains space for administrative staff and individual spaces for the three founding partners, while the remaining staff resides on the level above in an open studio environment. The aged brick walls of the studio space above are compactly lined with project information and models.

The practice was started by three collegiate friends just over twenty years ago in 1992. The practice is incorporated as a LLP (limited liability partnership) and is structured in a traditional way branching down from the directors at the top as a hierarchical staff with related titles. Originally specialising in retail refurbishment, the practice has grown to over thirty members and has developed a balance between new build and refurbishment work varying in scale and typology. Over time the office has adapted more formal protocols driven by an increasing need for them as a requirement to bid for projects (e.g. a quality assurance system that outlines guidelines for all work).

Project teams are generally structured based on the sector of work allowing for specialised knowledge and skills to be developed. In general, there is no fixed firm philosophy as each director is viewed to have their own perspective and style. There is a shared feeling that the work tries to embody a set of underlining themes: a) context specific, b) practical and c) a balanced set of views in aspiration towards a good level of design. This latent ethos is reflected in their starting point for each project, typically being a site analysis of external conditions. The informal approach assesses a site through a series of mental questions documenting the characteristics and quality of the surrounding area.

\section{The King's School in Chester}

The King's School in Chester spreads across more than 15 hectares as an eclectic conurbation of mostly single storey buildings. The school has occupied the current site since the 1960s and has developed over time as school needs have grown and evolved. CGL was asked to provide a masterplan for the school that would make better use of existing facilities and guide future development. In response, CGL provided the school with a 'development options' document. The document provides a more flexible approach to development as opposed to a masterplan which lays out a single vision. The document is organised as a menu of development opportunities that can be enacted as the school sees fit in the short, medium and long term- simultaneously it provides an overall understanding of the site, illustrating how each option ties into the larger picture as opposed to the piecemeal approach of the past. Building off the successful relationship, the school then approached CGL to review a feasibility exercise for the refurbishment of the theatre hall adjacent to the main entrance.

It was clear the school desired a versatile space, but the proposed solution by the school trust complicated access, ruined spacious qualities of the neighbouring dining hall and was limited to retractable seating. The original hall constructed in the 1960's consisted of a permanent stage and proscenium arch with plastic stackable chairs that provide a level of adaptability, but are time-consuming to store - creating a huge barrier to the use of the space for alternative purposes. In addition, a lightweight retractable partition closed the rear of the hall off from the main school foyer, but provided very poor acoustic separation. CGL saw a lot more potential in the space and worked diligently with the client to communicate how it could be better suited for its 
primary use as a theatre, serve a variety of uses, and save them approximately half a million pounds in comparison to their original study.

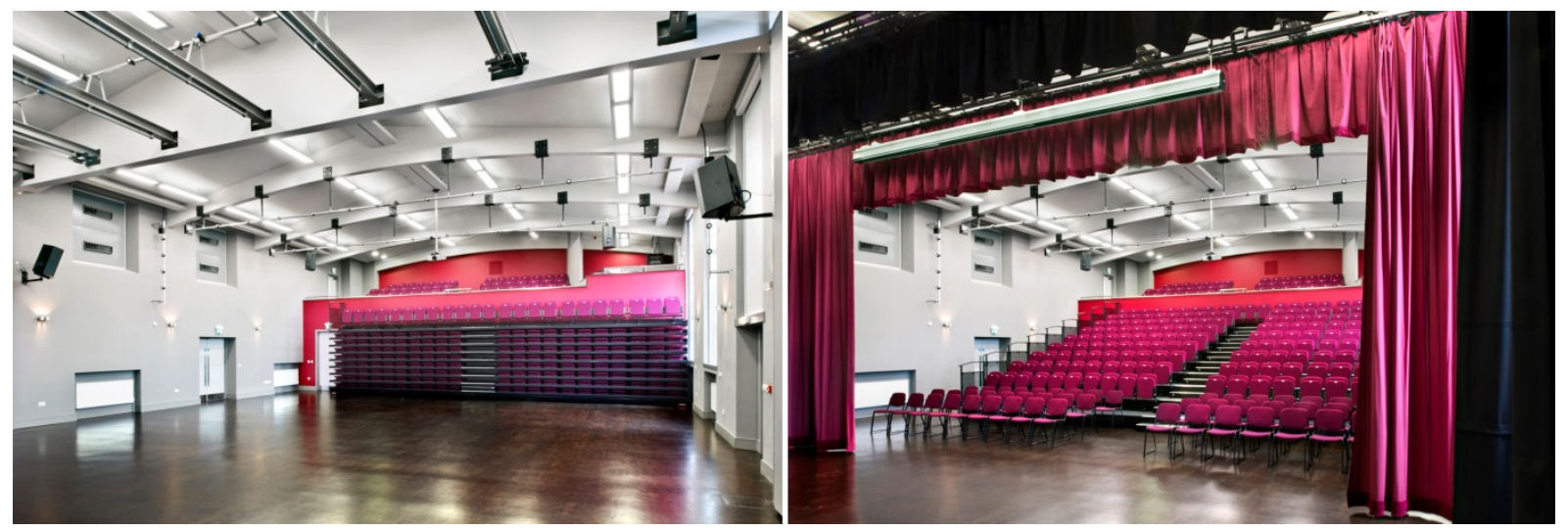

Figure 7 King's School Chester, multi-use hall, CGL Architects (Images courtesy of Jonathan Banks)

As part of refitting the theatre, the brief called for changing facilities, storage, staff offices and meeting rooms. The staff offices, meeting rooms and storage space were strategically located below the balcony making best use of the lower single storey height space and forming a stronger acoustical buffer between the theatre and the circulation space of the main foyer. Changing rooms and additional storage were placed at the opposite end, at the rear of the stage, allowing the remainder of the space to be unfixed with the installation of a retractable seating system, a retractable curtain system, removable staging, adaptable lighting rigs and movable side wings. The simple design concept placed the fixed spaces as bookends, maximising the open space and allowing the remaining 'stuff' inside the theatre to be versatile. The design particularly considered the speed and ease of transforming the space as they wanted to remove any barriers for change (e.g. seats can be fully open or retracted in 10 minutes by a single person). The full height moveable side wings can sit flush against the wall to open the space up, be fully opened to form part of the proscenium or set at a midpoint to act as sound deflectors for a musical performance. The staging is a modular solution that can be quickly added to or removed and a retractable blind system was installed to allow quick transformations to full black out and vice versa, allowing them to benefit from the large amount of natural light when appropriate.

In another example, the school wanted to use dark colours to help promote a theatrical atmosphere, but CGL convinced the client that lighter colours would support the use of the space for a variety of activities. Moreover, CGL illustrated to the school that if they increased the level of WC provision as part of the project they would not have to rely on other facilities within the school to meet public licensing requirements which enabled the school to hire the theatre for private use and keep the rest of the school closed off - reducing costs and management associated with external hire and increasing its attractiveness.

\section{Discussion}

The short descriptions of the three practices and the artefacts they produce provide two interrelated windows into practice culture. All three establish a tailored form of creativity through their organisational structure and spatial 
environment - e.g. one looks to exploit the qualitative benefits of a 'no rule', 'open to anything' approach while another maximises the quantifiable benefits of formal labels and professional qualifications - reflecting very different self-perceptions and design approaches. While aspects of formation, staff rewards and design inspiration overlap, the particular combination in each case creates a unique culture. Chosen locations - a retail space in a shopping centre, a shared community in an arts district and a secluded oasis in a business quarter - along with meticulously selected office décor (colours, materials, furniture, art and architectural objects) are material demonstrations that echo the contrasting practice cultures. Table 1 lists examples of emergent aspects of practice culture (architectural practice) and other human and non-human elements that influence the process and product (project specific, exogenous factors). The table provides examples that differentiate and align the elements across the three practices and can be considered further delineations of the three high-level cornerstones. Thus, they establish very different arenas for design to take place and as a result offer a different framework from which decisions within the design process and the resultant architecture are contingent to. So then, what happens at the intersection between practice and project, i.e. how does practice culture become intertwined within the designed product?

\begin{tabular}{|c|c|c|c|}
\hline & Make & ABA & CGL \\
\hline \multicolumn{4}{|c|}{ Architectural Practice } \\
\hline Philosophy & $\begin{array}{l}\text { Single and guiding concept, } \\
\text { not everything has to be a } \\
\text { 'white box' }\end{array}$ & $\begin{array}{l}\text { Physical \& Cultural } \\
\text { infrastructure, Architecture as } \\
\text { city building }\end{array}$ & $\begin{array}{l}\text { No fixed approach - practical, } \\
\text { balanced, robust concepts }\end{array}$ \\
\hline Structure & Flat, egalitarian, no badges & Hierarchical with titles & $\begin{array}{l}\text { Traditional 'tree' hierarchy with } \\
\text { titles, partnership model }\end{array}$ \\
\hline Role & $\begin{array}{l}\text { Design champion, problem } \\
\text { solver, instigator/pusher }\end{array}$ & Value adder, negotiator, & $\begin{array}{l}\text { Obtain planning permission, } \\
\text { resolve conflicting issues }\end{array}$ \\
\hline Learning & $\begin{array}{l}\text { No formal training, walk } \\
\text { around office and ask } \\
\text { others }\end{array}$ & $\begin{array}{l}\text { Regular external training, } \\
\text { practice trips }\end{array}$ & $\begin{array}{l}\text { Internal (informal and formal) } \\
\text { and External (formal) training } \\
\text { opportunities }\end{array}$ \\
\hline New work & $\begin{array}{l}\text { Invited competitions, } \\
\text { private commissions, } \\
\text { referral }\end{array}$ & $\begin{array}{l}\text { Open competitions, referral, } \\
\text { reputation, }\end{array}$ & $\begin{array}{l}\text { Framework arrangements, } \\
\text { referral, marketing, networking }\end{array}$ \\
\hline Design tools & $\begin{array}{l}\text { Artwork, digital } \\
\text { technology, physical } \\
\text { models }\end{array}$ & $\begin{array}{l}\text { 3D software, physical models, } \\
\text { animation software }\end{array}$ & $\begin{array}{l}\text { Sketches, Precedents, 3D } \\
\text { software }\end{array}$ \\
\hline $\begin{array}{l}\text { Protocols } \\
\text { (rules, policies) }\end{array}$ & No official rules & $\begin{array}{l}\text { office manual, everyone is } \\
\text { issued terms \& conditions } \\
\text { before they start }\end{array}$ & $\begin{array}{l}\text { Quality assurance system, } \\
\text { policies for health \& Safety, } \\
\text { equality, sustainability, ethics }\end{array}$ \\
\hline $\begin{array}{l}\text { Spatial } \\
\text { organisation }\end{array}$ & Multiple open spaces & Single open space & $\begin{array}{l}\text { Single open space with } \\
\text { individual offices for directors } \\
\text { and administration }\end{array}$ \\
\hline \multicolumn{4}{|c|}{ Project Specifics } \\
\hline Type of client & $\begin{array}{l}\text { Experienced long-term } \\
\text { owner, progressive } \\
\text { mindset }\end{array}$ & $\begin{array}{l}\text { Experienced, short-term } \\
\text { owner, conventional mindset }\end{array}$ & $\begin{array}{l}\text { Non-experienced long-term } \\
\text { owner/occupier, conventional }\end{array}$ \\
\hline Design brief & Push boundaries, openness & $\begin{array}{l}\text { Add clarity, manage } \\
\text { perceptions }\end{array}$ & $\begin{array}{l}\text { Expand beyond immediate } \\
\text { needs }\end{array}$ \\
\hline Budget & $\begin{array}{l}\text { Innovative thinking, capital } \\
\text { cost vs. long-term value }\end{array}$ & $\begin{array}{l}\text { Cancels the value they try to } \\
\text { add, a constraint }\end{array}$ & Cut costs, add value \\
\hline $\begin{array}{l}\text { Design team } \\
\text { collaboration }\end{array}$ & $\begin{array}{l}\text { Shared vision, good } \\
\text { engineers are critical, } \\
\text { geographical proximity is } \\
\text { important }\end{array}$ & $\begin{array}{l}\text { Quantity surveyors create time } \\
\& \text { cost constraints, competing } \\
\text { values, but are necessary to } \\
\text { grasp building complexity }\end{array}$ & $\begin{array}{l}\text { Hinges on trust, enables good } \\
\text { solutions, structural engineers } \\
\text { are allies, project managers can } \\
\text { form a communication barrier }\end{array}$ \\
\hline
\end{tabular}




\begin{tabular}{|l|l|l|l|}
\hline $\begin{array}{l}\text { Procurement } \\
\text { route }\end{array}$ & $\begin{array}{l}\text { Sets roles, values, sequence } \\
\text { of process }\end{array}$ & $\begin{array}{l}\text { Can limit communication and } \\
\text { design time, establishes design } \\
\text { team structure }\end{array}$ & $\begin{array}{l}\text { Framework arrangements } \\
\text { creates trust through repetitive } \\
\text { work, contractor-led routes } \\
\text { limits design }\end{array}$ \\
\hline Exogenous Factors & \multicolumn{2}{|l|}{} \\
\hline Social agenda & Client or policy driven & $\begin{array}{l}\text { Practice driven - material and } \\
\text { building life, mixed use }\end{array}$ & $\begin{array}{l}\text { Practice \& client driven - whole } \\
\text { life costs, energy demand, reuse }\end{array}$ \\
\hline $\begin{array}{l}\text { Policies \& } \\
\text { Regulations }\end{array}$ & $\begin{array}{l}\text { Drives agendas - } \\
\text { regeneration and mixed } \\
\text { uses }\end{array}$ & $\begin{array}{l}\text { Challenge conventions } \text { - } \\
\text { Planning permission, Zoning } \\
\text { (change of use), }\end{array}$ & $\begin{array}{l}\text { Establishes framework - density, } \\
\text { parking, negotiating tools, } \\
\text { standards, taxes }\end{array}$ \\
\hline Market & $\begin{array}{l}\text { Weak market currently, } \\
\text { reduced funding } \\
\text { opportunities, mixed uses } \\
\text { pushed value up }\end{array}$ & $\begin{array}{l}\text { Valuation practices, shifted } \\
\text { demand, limits risks }\end{array}$ & $\begin{array}{l}\text { Growing market, influenced } \\
\text { types of spaces, cost of } \\
\text { materials }\end{array}$ \\
\hline
\end{tabular}

Table 1 Emergent aspects of practice culture across the three practices

The project accounts focus on adaptability as a common thread to illustrate how a particular design criterion is mobilised (or not) in relation to the culture of the design practice. Table 2 summarises the mobilisation of adaptability within the three projects, illustrating the differences between who (driver), why (benefits) and the resulting position of adaptability in relation to the overall design concept.

\begin{tabular}{|l|l|l|l|}
\hline \multicolumn{1}{|c|}{ Adaptability } & \multicolumn{1}{c|}{ Make } & \multicolumn{1}{c|}{ ABA } & \multicolumn{1}{c|}{ CGL } \\
\hline Instigator & Client & Architect & Architect \\
\hline Beneficiary & Client & Client \& Community & Client \\
\hline Primary Benefit & Higher Financial return & Market options & Improved Use \\
\hline Secondary Benefit & Market options & Community Integration & Higher Financial return \\
\hline $\begin{array}{l}\text { Architect view } \\
\text { regarding adaptability }\end{array}$ & $\begin{array}{l}\text { sceptical; sits amongst a } \\
\text { milieu of design concepts }\end{array}$ & $\begin{array}{l}\text { Embracing; part of the } \\
\text { practice's agenda }\end{array}$ & $\begin{array}{l}\text { Interested but at a cost; } \\
\text { sees it as a good thing }\end{array}$ \\
\hline $\begin{array}{l}\text { Mobilisation of } \\
\text { Adaptability (project- } \\
\text { specific) }\end{array}$ & $\begin{array}{l}\text { Superseded by design } \\
\text { concept }\end{array}$ & Integral to design concept & Driver for design concept \\
\hline
\end{tabular}

Table 2 Mobilisation of Adaptability as a design characteristic

With the multi-use hall, CGL focused on using their expertise to provide the client the best solution, here increased adaptability promoted by the architect is translated into a means to exceed client expectations (improved use of theatre). The architect through on-going discussions with the client broadens the client's perspective towards developing a solution that is more adaptable for their future needs - encouraging the client to think beyond their direct needs of drama provision and how the space could be used effectively for other purposes. The narrative demonstrates the use of adaptability as a driver for the design concept to improve the functional use and provide additional financial returns (i.e. the architect's experience regarding adaptability sells a better asset to the school). By focusing on improving the asset from a financial and use perspective, all influences are tied to client needs (project specifics) - e.g. a potential exogenous obstacle, WC regulations, is absorbed by providing additional toilets. The project also illustrates examples of how certain design tactics that may not conventionally be linked to adaptability (e.g. colour selection, acoustics, daylight, access) can play a role in allowing a space to be used for different purposes and by different users. The path for CGL's interjection is unconventional through a consultation on a feasibility study, but attracts the client's attention by reducing costs, increasing the school's options and adding greater architectural quality. The project reflects the practice's three underlying themes (context, practical and good level of design) while offering a sound business proposition, 
reflecting the formal and business-orientated approach of the practice. With regards to the model, CGL's entry point finds itself through the project specifics portion of the triangle and aligns well with the strategic approach of Strong Experience and the practice values of a business-centred practice as the project narrative consistently illustrates how CGL uses its strong experiences to create/sell an improved asset.

With The Cube adaptability is driven from client experience; however, all design characteristics including adaptability are forced to adhere to the design concept. Adaptability as a client-led demand (project specifics) is filtered through the design concept (architectural practice) - the power of the initial painting serves as an artistic catalyst (not far removed from the artwork on the walls). Adaptability is pursued by the client to add financial value and broaden the tenant market; however, we see how adaptability (while a client aspiration) is provided at the expense of stabilising the 'perfect' cube. The narrative reveals how the client benefits from the deployment of certain adaptability tactics (e.g. transitional floors), but also exemplifies compromises at the client's discretion to allow the strong design concept to carry through - i.e. the client allows their aspirations for a versatile and convertible solution to be subordinated to their desire for an iconic building (of great 'delight'). For example, the preservation of the desired aesthetic for the courtyard comes at a cost of creating less adaptable residential spaces - the architectural practice with its 'strong ideas' trumps the functionality of the project specifics. When the design concept is not in jeopardy, a practical solution is allowed to surface without tension and provides the client with a desirable result that balances project specifics (operational maintenance) with exogenous factors (material warranty). The enmeshed narratives ground the practice as a Strong Idea organisation with a value system of a practice-centred business. Make's entry point is through the architectural practice corner with the resulting artefact remaining firmly anchored to the design vision.

For FPAC, ABA quickly coalesces adaptability with the physical and social context; adaptability here is integral as a means to provide the best solution not only to the client (market options) but to the community at large (use options). The mixture of uses, hours of operation, the building's role as part of a larger plan and historic narrative, all interweave the project in the larger social fabric of the locale within which it is situated, and even play a role in achieving planning permission (exogenous factors). FPAC showed how adaptability can be a physical attribute of the building and scale beyond, interweaving the wider social and physical landscape (e.g. design concept, exterior proportions, variety of uses, neighbouring sites). The narrative illustrates how a research-based approach can generate an adaptable solution mixing narrative, craft and uses to enhance the social appreciation of the building. The project is also rooted in a powerful design (materiality, tectonics). While successful, the project depiction notes a few examples where adaptability is subdued to project specifics (budget) - despite being subordinated the possibility for the solutions to be implemented later on remain. The narratives exemplify a strong alignment between $A B A$ 's internal philosophy as an architectural practice and the exogenous factors. Thus similar to Make, $A B A$ is reflected as a Strong Idea practice and a value system of a practice-centred business. However, while remaining a strong culture, the practice's entry point is through the exogenous factors corner.

The data revealed the practices' espoused values were enmeshed throughout the design journey and reflect the embodiment of the design criterion (adaptability) in their projects. The practice narratives reflect Schein's socio-material depiction of organisational culture conveying their beliefs, values and artefacts, while the 
project narratives echo the disposition of the practices - one could go as far as to cut and paste lines from the practice narrative and smoothly paste them into the project descriptions (and vice versa). It's worth noting that while the narratives included aspects of the material culture of the practices, they are not discussed as much here given our primary focus on the socio-cultural context of practice in relation to a particular design criterion. Nevertheless, the presentation of other influential human and non-human aspects are revealed in Table 1, the influence of which would offer a fruitful avenue for further research.

\section{Conclusions}

While an intertwinement of them all, the culture of each practice influenced the artefact to stress a particular meaning in each context - for Make it is a beautiful object, for ABA a piece of social infrastructure and for CGL a business asset. And thus, adaptability finds itself subdued, promoted, compromised and sold as part of the design process and the resultant architecture. And therefore the culture of practice is important to the resultant outcome and has the capacity to scale, evolve, prioritise and stabilise adaptability. The findings are not limited to adaptability as a design criterion and are representational of a dynamic design process. Our contribution extends the argument that design is entangled within its socio-cultural surroundings and grounds the culture of practice in the designed artefacts. It is clear that in understanding the way in which a practice handles decision-making contingencies, both endogenous and exogenous forces to the practice (and project) will together shape a practice disposition towards design (adaptability). Thus, design is situated - it cannot be completely understood in abstraction from the practice culture within which it is embedded. ${ }^{38}$ This supports Cuff's ${ }^{39}$ claim that office dialect, mores, activity patterns, power structure and roles influence design outcomes - seeing design practice as an active agent shaping design practise, unfolds the relationship between design philosophy and its manifestation in the designed solution. Organisational culture becomes highly relevant in the practice of design and is influential in the way the individual designer works.

In generalising to a theory of how the culture of practice influences (the adaptability of) the design solution, the research lens served as an informative way of structuring data and augmenting the relationship between practice and projects. The way practice culture emerges as an 'actor' in the building process will shape the way in which they handle the milieu of decision-making contingencies that burgeon distinctive responses to adaptability in the configuration and context of the building. The point of entry to the triangle defines the practice tendency; however a project can end up anywhere in the triangle, but there will be a stronger pull towards their dominant practice disposition. This will always be ameliorated by other influences, although the extent to which the practice disposition is distorted is dependent on the strength of itself (e.g. scale, role) and its capacity to align itself with the other two dimensions. Entry through the top of the triangle (exogenous factors) has a much stronger propensity to allow for adaptability to manifest as part of the designed artefact. A correlation can be made between the longevity of adaptability as a design characteristic that transcends beyond the initial project in an attempt to maximise the value of the built asset. Thus, design which is driven by a strong culture that embeds exogenous influences as part of their approach tends to provide more adaptable solutions as part of their quest to satisfy long-term, societal concerns. 
Given all three projects embodied adaptability to a certain extent, it's not surprising that all three practices are examples of the two design approaches (Strong idea and Strong experience) that tie to the exogenous factors corner (Figure 3). However, each practice enters the triangle from a different point, making their dispositions distinctively different. FPAC implements a mixture of social and commercial spaces to promote a variety of activities and creates a significant place that scales within and beyond the exterior walls. It is less about the form or innovative image of the building (while still important) and more about enhancing the (evolving) use of the building. A time-based view of design is an explicit part of their ethos, establishing a 'loose-fit' between programme and architecture.

\section{Notes}

\footnotetext{
${ }^{1}$ For examples see Albena Yaneva, Made by the Office for Metropolitan Architecture: An Ethnography of Design (Rotterdam: 010 Publishers, 2009), p. 14; Sophie Houdart and Minato Chihiro, Kuma Kengo, An Unconventional Monograph, (Paris: Editions Donner Lieu, 2009), p. 12; and Louis L. Bucciarelli, 'An ethnographic perspective on engineering design', Design Studies, 9 (1988) pp 159-168.

${ }^{2}$ Dan J. Sage and Andy Dainty. Understanding power within project work: the neglected role of material and embodied registers. Engineering Project Organization Journal, 2(4), (2012), pp. 202-215.

${ }^{3}$ For examples see Dana Cuff, Architecture: The story of practice. (Cambridge MIT Press, 1991); Stewart Brand, How buildings learn: What happens after they're built, (New York: Penguin, 1994) and Jeremy Till, Architecture Depends (Cambridge: The MIT Press, 2009).

${ }^{4}$ For examples see Peter Lloyd and Peter Deasley, "Ethnographic Description of Design Networks", Automation in Construction, 7 (1998) pp. 101-110; Mark Perry and Duncan Sanderson, "Coordinating joint design work: the role of communication and artefacts", Design Studies, 19 (1998) pp. 273-278; and Edward Robbins, 'Architecture and culture: a research strategy', Design Studies, 5(3), (1984), pp 175 -177.

${ }^{5}$ Cuff, p.4.

${ }^{6}$ Judith R. Blau, Architects and firms: A sociological perspective on architectural practice. (Cambridge: The MIT Press, 1984), p.ix.

${ }^{7}$ Andrew D. Brown, Martin Kornberger, Stweart R. Clegg and Chris Carter, 'Invisible walls and silent hierarchies: A case study of power in relations in an architecture firm.' Human Relations: 63(4) (2010), pp 525-549.

${ }^{8}$ Guy Julier, 'From Visual culture to Design Culture,' Design Issues: 22(1), (Winter, 2006), pp 64-76.

${ }^{9}$ Edger Schein, Organisational Culture and Leadership, (San Francisco: Jossey-Bass, 2004).

${ }^{10}$ Cuff, p.112.

${ }^{11}$ Kristina Lauche, 'Job design for good design practice,' Design Studies, 26(2), (March, 2005), pp191-213.

${ }^{12}$ Weld Coxe, Nina Hartung, Hugh H. Hochberg, Brian J. Lewis, David H. Maister, Robert F. Mattox, and Peter A. Piven, 'Charting Your Course: Master strategies for organizing and managing architecture firms', Architectural Technology, (May/June 1986), pp 52-58.

${ }^{13}$ Graham Winch and Eric Schneider, 'The strategic management of architectural practice', Construction Management and Economics, 11 (1993) p. 467.

${ }^{14}$ Ibid.

${ }^{15}$ Blau, p.4.

${ }^{16}$ Magali Sarfatti Larson, Behind the Post Modern Façade, (Los Angeles: University of California Press, 1993).

${ }^{17}$ Frank Jenkins, Architect and Patron. (London: Oxford University Press, 1961).

${ }^{18}$ Laurie Cohen, Adrian Wilkinson, John Arnold, and Rachael Finn, 'Remember I'm the Bloody Architect! Architects, Organizations and Discourses of Professions', Work, Employment, and Society, 19 (2005), p. 775.

${ }^{19}$ See Blau 1984 and Cuff 1991. For additional examples see Richard Gutman, Architectural practice: A critical view, (Princeton: Princeton Architectural Press,1988 and Bill Hubbard Jr, A Theory for Practice: Architecture in Three Discourses, (Cambridge: The MIT Press, 1995).

${ }^{20}$ Loose translation by Henry Wotton, The Elements of Architecture, (Springfield: F. A. Bassette Company, 1903).

${ }^{21}$ See for Thomas Gordon Smith, Vitruvius on Architecture, (New York: The Monacelli Press, 2004).

${ }^{22}$ David M. Gann, Ammon J. Salter and Jennifer K. Whyte, 'Design Quality Indicator as a tool for thinking', Building Research \& Information, 31 (5), (2003), pp. 318-333.

${ }^{23}$ Bernard Tschumi, Event-Cities 3: Concept vs. Context vs. Content, (Cambridge: The MIT Press, 2005).

${ }^{24}$ Brand, p.5.

${ }^{25}$ Robert Schmidt III, Toru Eguchi, Simon Austin and Alistair Gibb, Adaptable Futures: A 21st Century Challenge, Changing Roles - New Roles, New Challenges, (Rotterdam, Netherlands, 5-9 October 2009).

${ }^{26}$ For examples see Sara Jane Wilkinson and Richard Reed, 'The business case for incorporating sustainability in office buildings: The adaptive reuse of existing buildings,' In 14th Annual Pacific Rim Real Estate Conference, (Kuala Lumpur, Malaysia, 20-23 January, 2008); Craig Langston, Francis Wong, Eddie Hui and Li-Yin Shen, 'Strategic assessment of building adaptive reuse opportunities in Hong Kong', Building and Environment, 43 (2008), p. 1709; and Canadian Standards Association, Guideline for design for disassembly and adaptability in buildings. (Ontario: 2006), Z782-06.

${ }^{27}$ Schmidt III et al., p.1.

${ }^{28}$ For examples see Daniel Fletcher, Robert W. Brennan, and Peihua Gu, 'A Method for Quantifying Adaptability in Engineering Design', Concurrent Engineering, 17(4), (2009), pp. 279 - 289; and Soren Nielsen, Dynamisk Arkitektur. Arkitekten 10, (2010), pp.63-70.
} 
${ }^{29}$ Adrian Leaman, A. and Bill Bordass, 'Flexibility and Adaptability', In Designing better buildings, ed. Macmillan, S., (London: Spon Press, 2004), pp. 145-156.

${ }^{30}$ David Kincaid, Adapting buildings for changing uses: Guidelines for change of use refurbishment, (London: Spon Press, 2002).

${ }^{31}$ Brand, p.5.

32 James Barlow and Martina Koberle-Gaiser. Adaptability and innovation in healthcare facilities: Lessons from the past for future developments. HaCCIRIC (2009).

${ }^{33}$ Anna Dubois and Lars-Erik Gadde, 'Systematic combining: an abductive approach to case research', Journal of Business Research, 55, (2002), pp. 553-60.

${ }^{34}$ Anselm Strauss and Juliet Corbin, Basics of Qualitative Research: Grounded Theory Procedures and Techniques (2 ${ }^{\text {nd }}$ edn), (Thousand Oaks, CA: Sage, 1998).

${ }^{35}$ Kathleen M. Eisenhardt, 'Building theories from case study research', Academy of Management Review, 42 (1989), pp. $532-50$.

${ }^{36}$ C. P. Pathirage, Dilanthi Amaratunga and Richard Haigh, 'The role of philosophical context in the development of theory: Towards methodological pluralism' The Built and Human Environment Review, 1 (1), (2008), pp. 1-10.

${ }^{37}$ Dan Remenyi, Brian Williams, Arthur Money and Ethne Swartz, Ethné, Doing Research in Business and Management. An Introduction to Process and Method, (London: Sage, 1998).

${ }^{38}$ Yaneva, 2009; Houdart and Chihiro, 2009. See also Bruno Latour and Albena Yaneva, "Give me a gun and I will make all buildings move: an ANT's view of architecture" in Explorations in Architecture: Teaching, Design, Research, ed. R. Geiser, (Basel: Birkhauser, 2008), pp. 8089.

${ }^{39}$ Cuff, p.112. 